\title{
Morphology and Morphometrical studies on Semi lunar Heart valves of Indigenous Cattle (Bos indicus)
}

\author{
Akhtar $\mathrm{S}^{1}$, Hossain $\mathrm{FMA}^{2}$, Siddiqui MSI ${ }^{1}$, Alam $^{3}$ and Islam $\mathrm{MN}^{1} *$ \\ ${ }^{1}$ Department of Anatomy \& Histology, ${ }^{2}$ Department of Dairy \& Poultry Science and ${ }^{3}$ Department of \\ Agricultural Statistics, Sylhet Agricultural University, Sylhet-3100, Bangladesh.
}

[Received: 25 December 2010, Accepted: 30 March 2011]

\begin{abstract}
Twenty heart specimens of healthy indigenous cattle (Bos indicus) of different age group (04 groups) in Sylhet District were collected for gross morphology and morphometrical analysis of cusps or leaflets and papillary muscles to study the measurement of the length of the free margin of the cusps of the aortic and pulmonary valves and anatomical assessment for future bioprosthetic purpose for heterografting in the cardiac valvular human patients. It was found that the pulmonary valves consisted of three semilunar valve leaflets, the wall of the sinuses, the interleaflet triangles, the commissures and the sinotubular junction; whereas the aortic heart valve leaflets of indigenous cattle were three in number: right, left and noncoronary. Each leaflet of the valve has a central lamina fibrosa at their free margin of which the thickened part in the midpoint of the lunula formed the corpus arantii. The length of the right and posterior pulmonary cusp in this study was statistically significant $(\mathrm{p}<.005)$ but the length of the left pulmonary cusp was not significant in all age groups of animal. The mean len gth of the right coronary cusps (RCC), left coronary cusps (LCC) and non coronary cusps (NCC) was statistically not significant irrespective of their age groups of animal studied. This valve might be used for manufacturing tissue valve for Bioprosthesis.
\end{abstract}

Keywords: Indigenous cattle, heart valve, morphology, morphometry.

\section{INTRODUCTION}

The valves of the heart are located within the chambers of the heart and are critical to the proper flow of blood through the heart. The valves control the flow of blood through the heart by opening and closing during the contractions \& relaxation of the heart $[1,2]$. The valvar complex comprises the annulus, the leaflets, the tendinous cords, and the papillary muscles. The valve is obliquely located in the heart and has a close relation to the aortic valve and the pulmonary valve is immediately adjacent to the aortic valve ${ }^{[3]}$. The various heart valves have been shown to contract independently during different moments of the heart cycle, suggesting that compensatory adaptation mechanisms exist to mediate the timing and efficacy of heart valve closure ${ }^{[4]}$. Here, we review the current morphological knowledge of human and animal heart valve innervations for the morphology and morphometry of semi-lunar (SL) valves. Specific studies of the aortic heart valve of the heart of cattle, sheep, horse, dog ${ }^{[5]}$ and pig ${ }^{[6]}$ were carried out. The circular aortic orifice carried the aortic valve, which consisted of three semilunar cusps, and were stronger than those of the pulmonary valves of the bovine heart ${ }^{[7]}$. These valves consisted principally of three cusps, aortic annulus ${ }^{[8]}$, aortic wall, aortic root ${ }^{[9,10]}$, valsalva's sinus and sinotubular junction ${ }^{[11,12]}$.

In addition, ossa cordis were also present in the aortic annulus of the bovine heart ${ }^{[13]}$. The aortic valve is one of the valves of the heart. It is normally tricuspid, although in $1 \%$ of the population it is found to be congenitally bicuspid ${ }^{[14]}$. The native heart valves function as if they were simple tubes with sides that collapse ${ }^{[15]}$ when external pressure is applied. The tissue of aortic valve designed on the basis of the proved engineering principle that form follows function has better hemodynamics, flow dynamics stress distribution ${ }^{[16]}$, and durability when compared under identical in vitro conditions with an excellent commercially available tissue aortic valve [17,18].

The pulmonary valve is the semilunar valve of the heart that lies between the right ventricle and the pulmonary artery and has three cusps ${ }^{[19]}$. Similar to the aortic valve, the pulmonary valve opens in ventricular systole, when the pressure in the right ventricle rises above the pressure in the pulmonary artery. At the end of ventricular systole, when the pressure in the right ventricle falls rapidly, the pressure in the pulmonary artery will close the pulmonary valve.

Patients with significant native heart valve disease (HVD) often experience valvular stenosis, incompetence, or both, leading to progressive cardiac changes as well as secondary organ involvement ${ }^{[20]}$. In cases where native valve repair is not possible, patients must be treated by valve replacement ${ }^{[21]}$. Prosthetic heart valves (PHVs) have been in use for over 50 years and have undergone many changes since their inception [22]. Today, patients with a replacement of valve have a better quality of life ${ }^{[23]}$ when compared to those HVD patients with significant disease who are medically managed ${ }^{\text {[24]. }}$ The gross anatomical studies of the semilunar heart valve was carried out in different species of animals 
including cattle ${ }^{[25]}$, however, their anatomical studies in the indigenous cattle of Bangladesh which have possibilities for bioprostheses is yet to be done. Therefore, in the present research work, a range of anatomical techniques have been used in a broad correlative study of the bovine semilunar heart valves and their supporting structures and the major events involved in tissue of heart valves for future bioprosthetic use ${ }^{[26,27]}$.

\section{MATERIALS AND METHODS}

\section{Collection of Bovine Heart}

A total of 20 heart specimens were collected from twenty healthy indigenous cattle (Bos indicus) of different ages (06 moths, 18 months, 24 months and 30 months of age and 4 cattle for each age group) in Sylhet district immediately after slaughter with aseptic measures. After rinsing away the blood, the heart samples were kept in the balanced isotonic saline solution. The specimens brought to the Laboratory and stored in the refrigerator at $4^{\circ} \mathrm{C}$ until dissection. Each specimen consisted of pericardium, ascending aorta, and aortic root, four cardiac chambers with their valves, pulmonary artery and small parts of cranial and caudal venacavae.

\section{Dissection of Bovine Heart Valves}

The dissection was done in the Laboratory of the Department of Anatomy and Histology, faculty of veterinary science of Sylhet Agricultural University following a normal surgical procedure. After removing the aorta containing the aortic heart valve was dissected by adopting an aseptic measure. The aortic valve was separated from the cardiac mass carefully. Similarly the pulmonary valves were harvested by opening the four chambers of the collected heart specimen. Great care was taken during trimming of excess myocardium from the end of the aortic and other valve annulus or root. This was done by placing finger tightly into the cusps of the valves and then the ventricular myocardium muscle trimmed out by scissor slowly.

\section{Preservation of the Heart Valves}

The three aortic sinuses of each desired bovine aortic heart valve and pulmonary valves were gently packed with cotton wool to maintain the normal architecture of the leaflets of the aortic heart valve and then preserved in $10 \%$ formalin solution, formalsaline solution with cotton plug for maintaining the normal shape and architecture of tissue for gross anatomical study purpose.

\section{Gross Anatomical Study of the Heart Valves}

The gross anatomical studies of the heart valves of the indigenous cattle with their supporting structures were done with the following parameters:

The pulmonary valve

The gross morphological studies on three semilunar cusps of the pulmonary valve located in the pulmonary trunk at the base of the right ventricle and their supporting structures, e.g. Pulmonary root, sinuses etc.

\section{The aortic valve}

The aortic heart valve is named for the shape of its cusps. The cusps were semilunar in shape, passive soft tissue structures attached to the wall of the aorta. In the present study the gross morphology of the free surface of the cusps, corpus arantii (or nodulus of Arantus), commissures, attachment of the cusp with the aortic wall and fibrosal surface as well as ventricular surface of the cusps had been undertaken. The aortic root, sinuses, commissures, and the interleaflet triangles and the ossa cordis of bovine heart were also studied.

\section{Morphometrical assessment of heart valves}

Using a standard mathematical measuring scale and a cotton thread, the length of the left coronary cusp (LCC), right coronary cusp (RCC), and non-coronary cusp (NCC) of aortic and pulmonary valves were measured and record the data.

\section{Statistical analysis}

The measurements of the mentioned parameters of the aortic and pulmonary heart valves of the indigenous cattle were done and all the data were recorded for anatomical assessment. Statistical analysis of that data was done by SPSS (Statistical Package for the Social Sciences) program.

\section{RESULTS AND DISCUSSIONS}

\section{The Pulmonary Valve}

It was observed that the pulmonary root was the first part of the pulmonary trunk, from the insertion of the pulmonary annulus in the right ventricular myocardium. It was also found that the pulmonary valve consisted of three semilunar valve leaflets, the wall of the sinuses, the interleaflet triangles, the commissures and the sinotubular junction (Figure 1). The length of the right pulmonary cusp in the present study was measured $14.4 \pm .55 \mathrm{~mm}, 15.4 \pm .55 \mathrm{~mm}$, $16.4 \pm .55 \mathrm{~mm}$ and $17.4 \pm .55 \mathrm{~mm}$ and the left pulmonary cusps was measured $12.4 \pm .89 \mathrm{~mm}$, $13.2 \pm .84 \mathrm{~mm}, 14.2 \pm .84 \mathrm{~mm}$ and $15.2 \pm .84 \mathrm{~mm}$ and the length of the posterior pulmonary cusps was measured $12.4 \pm .55 \mathrm{~mm}, 13.4 \pm .55 \mathrm{~mm}, 14.4 \pm .55 \mathrm{~mm}$ and $15.4 \pm .55 \mathrm{~mm}$ at year1, year1.5, year2, and year2.5 age groups respectively. The length of the right and posterior pulmonary cusp in the present study was statistically significant $(\mathrm{p}<.005)$ but the length of the left pulmonary cusp was not significant in all age groups of animal. The length of the three semilunar cusps of the pulmonary valve of different age group of cattle was presented in the table 1 .

In connection of the structure of pulmonary valve, the same findings but they also reported that the sinuses of the aorta are named according to the coronary arteries with their ostia (left and right 
coronary sinus), and the sinus without a coronary ostium is the noncoronary sinus ${ }^{[5,25]}$. The pulmonary sinuses are named by their relationship to the aortic sinuses: left facing, right facing, and nonfacing sinuses.

Table 1: Length $(\mathrm{Mean} \pm \mathrm{SE})$ of the length of the three semilunar cusps of the pulmonary valve of different age group in $\mathrm{mm}$ of the total number of indigenous cattle $(\mathrm{n}=20)$

\begin{tabular}{|c|c|c|c|c|c|c|}
\hline Age groups & RPC(MeantSE) & P-value & LPC(Mean $\pm \mathrm{SE})$ & P-value & PPC(Mean \pm SE) & P-value \\
\hline 01 year & $144+5$ & \multirow{3}{*}{$.002^{* *}$} & & \multirow{4}{*}{.152} & $124+5$ & \multirow{4}{*}{$.002^{* *}$} \\
\hline 1.5 years & $\begin{array}{l}14.4535 \\
15.4 \pm .55\end{array}$ & & $\begin{array}{l}12.4 .89 \\
13.2 \pm .84\end{array}$ & & $\begin{array}{l}12.4 \pm 53 \\
13.455\end{array}$ & \\
\hline 2 years & $16.4 \pm .55$ & & $14.2 \pm .84$ & & $14.4 \pm .55$ & \\
\hline & $17.4 \pm .55$ & & $15.2 \pm .84$ & & $15.4 \pm .55$ & \\
\hline
\end{tabular}

\section{Aortic valve:}

Aortic hearts valves of indigenous cattle in the present study examined possesses three cusps and semilunar in shape (Figure 2). The mean lengths of the right coronary cusps (RCC) were $25.2 \pm 2.59 \mathrm{~mm}$, $28 \pm 2.92 \mathrm{~mm}$, and $31.2 \pm 4.2 \mathrm{~mm}, 32.8 \pm 3.03 \mathrm{~mm}$. The left coronary cusps (LCC) were $25.6 \pm 2.97 \mathrm{~mm}$, $28.2 \pm 2.28 \mathrm{~mm}, 28.8 \pm 4.38 \mathrm{~mm}$ and $32.4 \pm 5.32 \mathrm{~mm}$. The non coronary cusps (NCC) were $22.6 \pm 1.14 \mathrm{~mm}$, $25.8 \pm .84 \mathrm{~mm}, 30 \pm 4.85 \mathrm{~mm}$, and $32.4 \pm 3.51 \mathrm{~mm}$ at year1, year1.5, year2, and year2.5 age groups respectively (Table 2). The mean length of the right coronary cusps (RCC), left coronary cusps (LCC) and non coronary cusps (NCC) were statistically not significant in all age groups of animal studied.

Table 2: Length (Mean \pm SE) of the free margin of the cusps of aortic heart valve of different age group in $\mathrm{mm}$ of the total number of indigenous cattle $(\mathrm{n}=20)$

\begin{tabular}{|c|c|c|c|c|c|c|}
\hline $\begin{array}{c}\text { Age } \\
\text { grou } \\
\text { ps }\end{array}$ & $\begin{array}{c}\mathrm{RCC}(\text { Mean } \\
\pm \mathrm{SE})\end{array}$ & $\begin{array}{l}\text { P- } \\
\text { va } \\
\text { lu } \\
\text { e }\end{array}$ & $\begin{array}{c}\mathrm{LCC}(\mathrm{Me} \\
\mathrm{an} \pm \mathrm{SE})\end{array}$ & $\begin{array}{l}\text { P- } \\
\text { val } \\
\text { ue }\end{array}$ & $\begin{array}{c}\mathrm{NCC}(\mathrm{Mea} \\
\mathrm{n} \pm \mathrm{SE})\end{array}$ & $\begin{array}{l}\text { P- } \\
\text { val } \\
\text { ue }\end{array}$ \\
\hline 01 & & \multirow{5}{*}{$\begin{array}{l}.4 \\
66\end{array}$} & $25.6 \pm 2.9$ & & & \multirow{5}{*}{.11} \\
\hline $\begin{array}{c}\text { year } \\
1.5\end{array}$ & $25.2 \pm 2.59$ & & $\begin{array}{c}7 \\
28.2 \pm 2.2\end{array}$ & & $22.6 \pm 1.14$ & \\
\hline $\begin{array}{c}\text { years } \\
2\end{array}$ & $28 \pm 2.92$ & & $\begin{array}{c}8 \\
28.8 \pm 4.3\end{array}$ & $\begin{array}{l}.40 \\
8\end{array}$ & $25.8 \pm .84$ & \\
\hline years & $31.2 \pm 4.2$ & & 8 & & $30 \pm 4.85$ & \\
\hline $\begin{array}{c}2.5 \\
\text { years }\end{array}$ & $32.8 \pm 3.03$ & & $\begin{array}{c}32.4 \pm 5.3 \\
2\end{array}$ & & $32.4 \pm 3.51$ & \\
\hline
\end{tabular}

*Indicates $\quad$ significant $\quad(\mathrm{p}<0.01), \quad * *$ Indicates statistically significant $(\mathrm{p}<.005) ; * * *$ Indicates highly significant $(\mathrm{p}<.001)$.

It is observed that the aortic heart valve leaflets of indigenous cattle were three in number: right, left and noncoronary. Each leaflet of the valve has a central lamina fibrosa at their free margin of which the thickened part in the midpoint of the lunula formed the corpus arantii (Fig 1). Similar findings were reported in another study ${ }^{[13,14]}$; in human indicating that morphologically the aortic heart valve of human and animals are similar. This result shows future possibilities of bioprosthesis. The aortic heart valve possesses three semilunar leaflets (Fig 2) and these were thicker and stronger than pulmonary valve in the present study, which was similar to the report in bovine ${ }^{[5,7]}$ and in human heart ${ }^{[28]}$. Similar results were also described in horse, dog and pig ${ }^{[5]}$. Inadequate congenital defect of human heart valves also reported in some studies ${ }^{[14]}$. Regarding the length of the free margins of the cusps of the aortic valve, few variations of the intercommissural distances of human hearts also observed and showed that the RC sinus, however, was the largest one followed by the NC and LC sinuses [29]. This variation between human and bovine heart owing to the presence of ventricular septum covering the aortic heart valve annulus. Regarding the length of the free margin of cusps of the aortic valve that found in human and bovine heart, respectively ${ }^{[30]}$. The fibro cartilaginous, irregularly triangular and semi osseous structures, the ossa cordis was found in the aortic ring or annulus and the adjacent part of the ventricular wall of bovine heart.

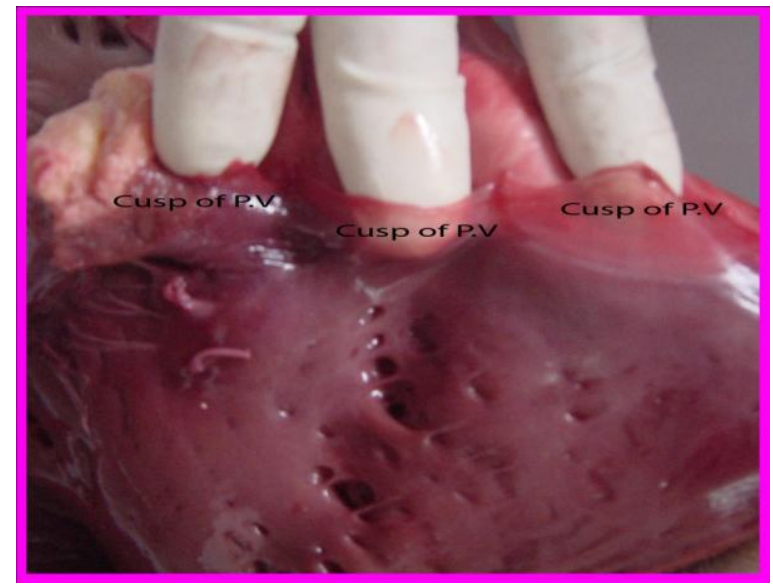

Figure 1: Pulmonary valve opened showing three semilunar cusps which were indicated by three digits in the figure (cusp of pv).

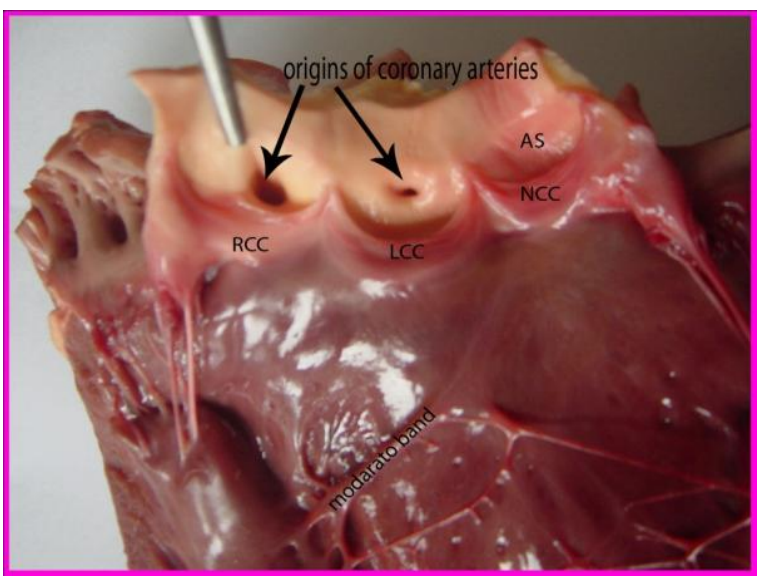

Figure 2: The mean length of the right coronary cusps (RCC), left coronary cusps (LCC) and non coronary cusps (NCC) were statistically not significant in all age groups of animal studied

The similar findings were noted in some studies with the presence of ossa cordis in the aortic fibrous ring of the aortic valve ${ }^{[13,31]}$. In this regard literatures 
were not available regarding the ossa cordis of human and other domesticated animals suggesting that the ossa cordis may be confined within the heart of bovine.From the above findings it could be included that the detailed gross morphology and morphometry of cardiac valves of indigenous cattle will be useful in improving the knowledge regarding the hemodynamic function of the heart and as well as in the field of bioprosthesis.

\section{REFERENCES}

1. Padula RT, Cowan GS and Camishion RCJ (1968). Photographic analysis of the active and passive components of cardiac valvular action. $J$ Thorac Cardiovasc Surg. 56(6):790-798.

2. Borin C, Danial Banhercke and Andre Weyns (2006). Innervation of the atrioventricular and semi-lunar heart valves;a review. Acta cardiol. 61(4):463- 69.

3. Silver MA and Roberts WC (1985). Detailed anatomy of the normally functioning aortic valve in hearts of normal and increased weight. American J. Cardiol. 55: 454-461.

4. Bashey RI, Torii S and Angrist A (1967). Agerelated collagen and elastin content of human heart valves. J Gerontol. 22(2):203-208.

5. Getty R (1975). Sisson and Grossman`s The anatomy of the domestic animals. Vol. 1.5th. edn. W.B. Saunders Company, Philadelphia, London, Toronto; pp: 962.

6. Housman LB, Pitt WA, Mazur JH, Litchford B and Gross SA (1978). Mechanical failure (leaflet disruption) of a porcine aortic heterograft: rare cause of acute aortic insufficiency. J. Thorac Cardiovasc Surg. 76(2):212-213.

7. Trotter DM and Lumb JW (1958). Bovine Anatomy. 2nd. edn. Burgess Publishing Company, 426 South 6th. Street, Minneapolis, pp; 123.

8. James McMorran (2004). Anatomy of Aortic valve annulus. General Practice Note Book- A UK Medical Encyclopedia on the World Wide Web (http://www.gpnotebook.co.uk)

9. Anderson RH (2000). Clinical anatomy of the aortic root. Heart J. 84:670-673

10. Berdajs D, Lajos P and Turina M (2002). The anatomy of the aortic root. J. Cardiovasc. Surg. 10(4): 320-327.

11. Thubrikar MJ, Nolan SP, Aouad J and Deck JD (1986). Stress sharing between the sinus and leaflets of canine aortic valve. Annals Thorac. Surg. 42: 434.

12. Sutton J P, HO SY and Anderson RH (1995). The forgotten interleaflet triangles: A review of the surgical anatomy of the aortic valve. Annals Thorac. Surg. 95: 419- 427.

13. Islam MN, Mazumder MS, Islam KN, Mahbube-Elahi ATM and Khan SR (2002). Investigation of bovine aortic valves in cardiac research for bioprosthetic purpose. Pakistan J. Bio. Sci. 5(1): 101-103.

14. Angelini A, Ho SY, Anderson RH, Devine WA, Zuberbuhler JR, Becker AE and Davies MJ (1989). The morphology of the normal aortic valve as compared with the aortic valve having two leaflets. J. Thorac. Cardiovasc. Surg. 98: 362-367.

15. Dainese L, GianLuca P, Fabio B and Paolo B (2003). Aortic Valve: do its nervous and contractile elements have any role? Fetal Heart J. 4 (11): 810-812.

16. Emery RW, Anderson RW, Lindsay WG, Jorgensen CR, Wang $\mathrm{Y}$ and Nicoloff DM (1979). Clinical and hemodynamic results with the St. Jude medical aortic valve prosthesis. Surg Forum.30:235-238.

17. Bellhouse B and Bellhouse F (1969). Fluid mechanics of model normal and stenosed aortic valves. Circ Res. 25(6):693-704.

18. Martin TR, Tindale WB, van Noort $R$ and Black MM (1981). In vitro heart valve evaluation: fact or fantasy? Trans Am Soc Artif Intern Organs. 27:475-479.

19. McMillan IKR, Daley $\mathrm{R}$ and Matthews MB (1952). The movement of aortic and pulmonary valves studied post mortem by colour cinematography. Br Heart J. 14(1):42-46.

20. Butany J, Fayet C and Ahluwalia MS (2003). Biological replacement heart valves: identification and evaluation. Cardiovasc Pathol. 12:119-139.

21. Butany J, Ahluwalia MS and Munroe C (2003). Mechanical heart valve prostheses: identification and evaluation (erratum). Cardiovasc Pathol. 12:322-44.

22. Tindale WB, Black MM and Martin TR (1982). In vitro evaluation of prosthetic heart valves: anomalies and limitations. Clin Phys Physiol Meas.3 (2):115-130.

23. Wain WH, Greco R, Ignegeri A, Bodnar E and Ross DN (1980). 15 years experience with 615 homograft and autograft aortic valve replacements. Int J. Artif Organs. 3(3):169-172.

24. Ross DN (1967). Replacement of aortic and mitral valves with a pulmonary autograft. Lancet. 4; 2(7523):956-958.

25. Huysmans HA (2004). Animal trials for heart valve substitutes. J. Heart Valve Dis. 13 (Supplement 1): S4-S6. 
26. Emery RW and Nicoloff DM (1979). St. Jude Medical cardiac valve prosthesis: in vitro studies. J. Thorac Cardiovasc Surg. 78(2):269276.

27. Kaiser GA, Hancock WD, Lukban SB and Litwak RS (1969). Clinical use of new design stented xenograft heart valve prosthesis. Surg Forum. 20:137-138.

28. William PL (1995). GRAY'S Anatomy. 38th edn. USA Shurchill Livingstone Inc. 650 Avenue, New York. N. Y. 10011; 1487-1488.

29. Vollebergh FEMG and Becker AE (1977). Minor congenital variations in cusp size in tricuspid aortic valves. Possible link with isolated aortic stenosis. Br. Heart J. 39: 10061011.

30. Islam MN, Khan MZI, Khan SR and Haque MA (2006). Gross anatomy of the aortic valve of indigenous cattle (Bos indicus) of Bangladesh. Bangl. J. Vet. Med. 4 (1): 31-37.

31. Khan SR and Islam MN (1991). Studies on the prospect of Bioprostheses by Bovine Aortic Valve for Human use. BMRC Bulletin; XVII: 75-80. 